\title{
Performing Elderliness - Intra-actions with Digital Domestic Care Technologies
}

\author{
Sisse Finken ${ }^{1}$ and Christina Mörtberg ${ }^{2}$ \\ ${ }^{1}$ Department of Informatics, University of Oslo, Oslo, Norway \\ finken@ifi.uio.no \\ ${ }^{2}$ Department of Informatics, Linneaus University, Kalmar/Växjö, Sweden \\ christina.mortberg@lnu.se
}

\begin{abstract}
We discuss the process of meeting digital technology when entering a senior age, by taking a closer look at how different modes of independence and elderliness are (co-)constituted in relation to digital domestic care technologies. Specifically, we suggest reading independence and elderliness as shaped by both the discursive and the material. Our starting point is the notion of intraaction as introduced in Feminist Technoscience. Thinking through use and design of digital technology from a standpoint of Feminism prompts us to widen the perspective on living with such technologies and, thusly, to raise questions about the process of coming of age as an independent person with such care technologies.
\end{abstract}

Keywords: Performativity, intra-action, elderliness, digital care technology, smart house, participatory design.

\section{Introduction}

The upcoming change in demography, the so-called tidal-wave-of-elderly, is expected to bring about socio-economic challenges in Scandinavia as well as in other countries. In meeting such changes health care services have turned to digital technology and moved from public institutions to private homes. With such move senior citizens are provided an opportunity to live independently in their own homes, rather than living in public eldercare facilities or nursing homes. Such new technology-equipped homes bring about possibilities for senior citizens to continue their daily life with all the good that living and being at home can bring. In an effort to meet today's socioeconomic challenges, the design and implementation of digital care technologies are increasing and becoming part of public welfare programs aiming to offer good care and services to societies' older population [1, 2]. Remmers [3], for example, argues that information and communication technology (ICT) is necessary to support older people in need of care, their relatives, and care workers.

In addition to an increased focus on ICT offered in support of aging and wellbeing, new understandings about prevailing norms and values relating to older people have emerged. In a co-design project (the Senior Interaction project [4]) concerning social 
network and interaction among senior citizens, the researchers became aware that the seniors studied in the project did not identify as elderly but that they talked about other people as elderly and in need of digital technologies. In drawing on the experiences gained during that project Brandt et al. [4] suggest using the notion of situated elderliness. They propose this as a way of honoring seniors' experiences, in illustrating how elderliness is situated in a practice, and how it is something that comes into existence when people and technology meet.

Barad's [5] notion of intra-action forms a starting point for our discussion on independence, performativity, and care technology. We contribute new empirical material generated in Norway and Sweden, some of which derives from a study of lived experiences in a smart home care unit, the other of which derives from a workshop with seniors that elicited views about a possible future living with digital domestic care technologies. We have chosen to bring in these two different examples together in an effort to show how care technologies create realities through the inclusions and exclusions inherent in their designs, and how elderliness and independence evolve in unison with both discourses and materiality.

The paper is structured as follows. First we introduce the concepts of intra-action and performativity and explain how we have found them useful. We then situate digital domestic care technologies in relation to those concepts. Next we delineate the two empirical studies, their respective methods, and their respective analyses. We then enter the two empirical grounds. We conclude with specific findings from our research and some implications for design.

\section{Intra-action and Performativity}

We use the notion intra-action [5] as an entrance to discussing how elderliness and independence are constituted in performance when senior citizens meet digital domestic care technologies. As a concept intra-action raises methodological questions that are relevant both when studying practices and when designing for everyday use of technology, for it maintains that both subjects and objects should be taken into account and accounted for as bringing about agency. Karen Barad's notion of intraaction differs from the notion of 'interaction' that is more commonly used in design studies. Interaction implies a relation between pre-existing humans (subjects) and technologies (objects) in which agency is a human or a technological attribute [5, p. 139]. The notion of intra-action, in contrast, suggests that subjects and objects come into existence only when and as they encounter each other. Lucy Suchman [6] captures the distinction: "Whereas the construct of interaction suggests two entities, given in advance, that come together and engage in some kind of exchange, intra-action underscores the sense in which subjects and objects emerge through their encounters with each other." [6, p. 267, original italics]. Thus, with the notion of intra-action, "Nothing is delimited as a separate entity. Everything is always engaging something else, in specific ways designated by the concepts: intra-activity, i.e. matter and meaning, object and subject, nature and culture are all mutually articulated and mutually entangled." [7, p. 68]. 
Within the notion of intra-action we get an understanding of Barad's [5] grasp of 'performativity', which specifies by considering matter on par with discourse. This is captured by Heckman [8]: "Barad's goal here is to formulate a materialist theory of performativity that, while not denying the role of discourse that Butler emphasizes, also does not deny the role of the material. In contrast to Butler's concept, Barad's agential realist elaboration of performativity allows matter its due as an active participant in the world's becoming (2007:136)." [p. 76, original italic].

Integrating the concept of intra-action with a feminist methodology for studying design and use is helpful as we also seek to following Bardzell \& Bardzell [9] who ask: "who are involved, and in what ways?" [p. 682]. Bringing into view an understanding of the becoming of objects and subjects, and how in orchestration they bring about particular re-configurations, also emphasizes the significance of who and what is included/excluded in the practices and activities [5] of design and use. There are no neutral positions [10], choices, involvements, or exclusions. That is, boundary making has "ontological implications" [8, p. 73].

Such insights are important for the analytical aim of this paper in terms of understanding how digital domestic care technologies blurs heterogeneity in a social group of people, who, with reference to [4], do not identify as elderly and in need of technologies.

In positioning ourselves at the crossroad of informatics and feminist science and technology studies we propose to understand interactions between humans and technology as material-discursive practices, in which materiality and meaning come into being when humans and technology intra-act [5]. We use intra-action as a starting point in our discussion of meetings between subjects and objects and the reconfigurings that come into being through them (intra-actions). We hope to understand how 'elderliness' and 'independence' come about through such intra-actions (performativity); how the design of care technologies create realities through inclusion and exclusion; and how these realities are enacted and acted upon by mundane artifacts, senior citizens, care workers, researchers, and their research methods.

\section{Digital Domestic Care Technologies}

Due to asymmetrical power relations in society feminist scholars have generated knowledge about the gendering of (information) technology and the co-construction of gender and technology, e.g. [1]. In doing so feminist scholars have developed a pluralistic understanding of gender-technology relations [1]. Although we build on this knowledge in the present paper, we keep our main focus on performativity and intra-action.

In our previous work $[11,12]$ we have described how smart home technology is designed and implemented in homes of and for older people in Scandinavia. The implementation takes place in an effort to meet socio-economic challenges that follow from the so-called tidal-wave-of-elderly [13]. These challenges are met by way of reorganizing health care services, moving them from public institutions into homes [1], [14]. Besides meeting socio-economic challenges, smart homes bring about 
possibilities for living independently at home: "Smart homes offer the promise of increased independence and reduced need for caregiver support in the home." [2, p. 210]. In order to live at home for as long as possible, older people come to live with digital devices such as alarms, detectors, and sensors that monitor bodily movements and/or (unwanted) phenomena such as smoke, water, and/or heat. These digital technologies communicate via Internet or mobile connections, and give feedback on computer screens, mobile phones, or other mobile devices according to predefined actions and/or the very absence of them [15, 16, 17]. According to Lopez et al., "Caring depends on some form of security. [...]. It is a process of becoming, but one never quite gets there, as the safety provided by the home telecare service is always emerging, but never reached. That is to say, it depends on practices, technologies and bodies that follow different logics - security and care - at the same time, in a delicate balance." [18, p. 87].

In smart home seniors come to live independently with the aid of inbuilt care technologies. Simultaneously, these care technologies introduce an economy of normativity by which residents come to perform a specific caring self in order for the technology to remain a caring aid [12]. That is (in pointing to an example with bed alarms, which we previously have used $[11,12])$ : the act of leaving the bed during night and not returning within the programmed time frame prompts the triggering of an alarm. Such triggering is productive when the person needs help, but rather counter-productive if the person just wants to sleep somewhere else in the house [19]. In this case, the person living at home materializes an object that can be measured by technology (see also [20]). In such measuring the heterogeneity of elderliness and independence is blurred. In other words, "Multiple positions exist at the same time, which means that identities are shaped in tensions between various positions; thereby, identities are neither uniform nor fixed but fragmented ([21]; [22])." [23, p. 163]. One such position comes about through intra-action with the care technology in the smart home. Thus, even though senior citizens use technology in their homes to support wellbeing and autonomy, it is also important to remember that they are not a uniform group; rather, they are a heterogeneous group with various wishes, demands, and expectations [24], who are situated in different spaces and time of different materialdiscursive entanglements [5].

In the next section we introduce our current fieldwork settings and our methods for generating and analyzing our material.

\section{Empirical Settings - Generating Material}

The workshop was held in December 2011 as part of the research project Sustainable Ways of Living with Technologies - designing with and for senior citizens and caregivers. The intention of the project was to design services with and for senior citizens in order to facilitate their day-to-day life and support wellbeing. The theme in the workshop was A Good Day, and included activities and technologies used during a good day. Three seniors, Alma, August, and Beathe, and two facilitators participated in the workshop. At the time of the workshop, the seniors were between 68-79 
years old. The seniors all lived in their own homes without help (neither manual nor digital domestic care services). The facilitators asked the participants to clarify some images (brought along by the researchers from magazines, newspapers, etc.) and their daily activities. The workshop was recorded after receiving permission to do so.

The participative methods used were cartographic mappings, which consist of sharing the created visual narratives by telling the other participants about mappings and future scenarios. The empirical material used in this paper is from the last activity "imagining the future." However, the scenarios have to be considered in relation to the other activities and methods used during the entire process, that is, the doings and actions taking place in the workshop or in material-discursive practice [5].

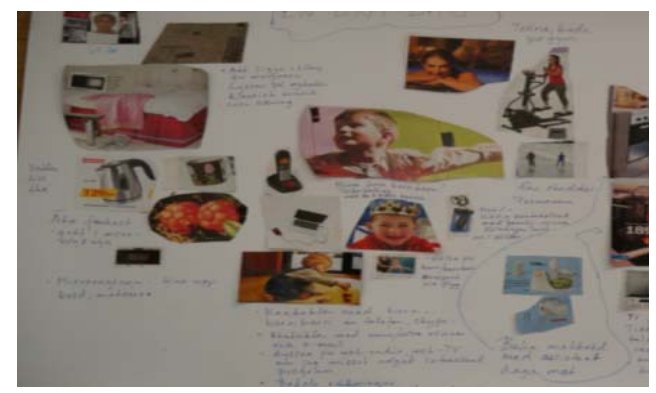

Fig. 1. Cartographic mapping. Photo: Mörtberg.

The cartographic mapping method, developed by [25], see also [26], was the first activity held after the participants and the project were introduced. In the mappings the participants illustrated a Good Day from the morning to the evening, activities they participate in, who they meet, what kind of technologies they use to facilitate their daily lives, etc. The method is inspired by both ethnographic studies and participatory methods used and developed in Participatory Design, see Fig. 1.

The events from the smart house were generated as part of a larger research-project Autonomy and Automation in an Information Society for All. The smart house is a new build care unit consisting of 91 flats. It opened in the early fall of 2012, and is certified as a 'care plus' unit, which means that safety, security, wellbeing, quality of life, and independency are central issues. According to the local municipality, senior citizens aged 67+ having impairments (e.g. rheumatism) and/or disabilities (e.g. difficulties with seeing) can rent their own flat in care plus units. In this way, a care plus home is something halfway between a private home and a nursing home [27, 28].

Interviews, observations, and photography were carried out with and among residents, technologies, and employees of the smart house in different situations (e.g. at home, touring the house, during work) and at different events (e.g. bingo, craft work, literature circle, and exercising in the smart gym). With a particular interest in understanding negotiations, translations, and displacements that follow when care technologies move in and are to find their place among caregivers and residents.

When analyzing our material we have engaged in readings of meetings between subjects and objects and their re-configurings. In such meetings we have especially focused on how 'elderliness' and 'independence' come about in intra-actions and we 
have tried to understand how the design of care technologies creates realities in virtue of what they include and exclude. Within this, 'independence' and 'elderliness' are themselves instantiations of the present that are enacted and acted upon by us. In this way, we have been sensitized to specific readings of events and situations encountered in the field. Indeed, in line with [5], we could say that our mere presence (as ethnographer in the smart house and designer of a participative work shop) is part of the current focus on care politics, care work, and living, doing, care technology. As also noted by [29], "we want to emphasize that the "choice" of phenomenon and the "choice" of entities to be selected and foregrounded as enacted and enacting forces in the analysis (whether papers, architecture, technology, subjectivity, emotionally, socio-cultural categories, normativities, or something entirely different) depends on the researcher, on the research ambition, and ultimately on how the phenomenon in focus is demarcate and defined." [p. 351].

\subsection{Smart House - Lived Experiences}

In this section we offer three examples from our fieldwork in an attempt to demonstrate how the concept of intra-action informed our readings of events in the field.

(Example 1) When we first entered the smart house in the early fall of 2012 our attention was drawn to the entrance door of the house, Fig. 2.

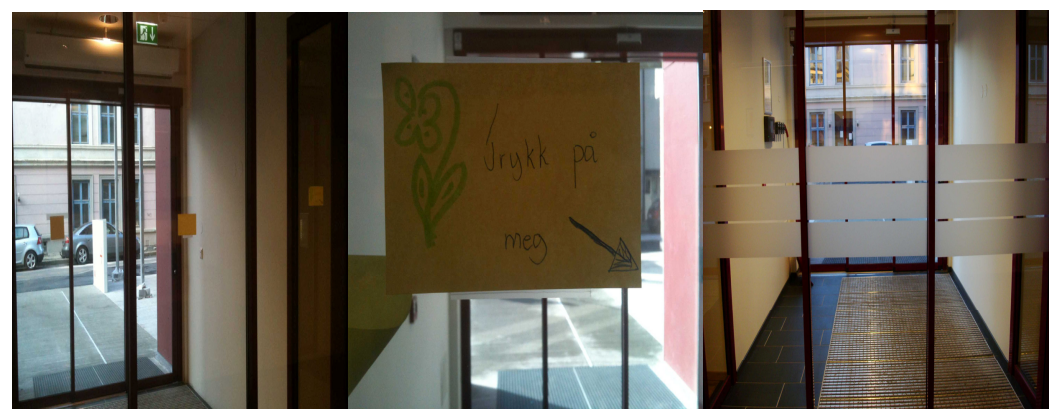

Fig. 2. The door with Post-it notes and tinted foil. Photos: Finken

When taking photos, 'interacting' with the door, thinking about displacements in design, talking with a care worker on a later occasion, and in analyzing our material from a standpoint of in- and exclusions, we learned about how new configurations of design and care work come about in encounters between subjects and objects.

On the large, glass, transparent entrance door, three Post-it notes were glued up. This entrance door opens automatically when one walks from outside and in; but when leaving the building, the door does not open automatically. One needs to push a button, placed to the right, at a lower position than can be reached by wheelchair. When pushing the button, the door slides open, and stays open until you are outside. Unfortunately, rather than stopping in front of the door and pushing the button, residents had been walking straight into the glass. Luckily nobody was hurt in such encounters with the too transparent and not visible glass door. To prevent accidents 
from occurring, the care workers had glued the Post-it notes up on the glass door (interview with care worker, October 2012). The door was later 're-designed' by adding tinted foil.

We read this as an example of how in-and exclusions in the design of technology have consequences for what becomes. The transparency of the door's can be said to be hindrance to enter into the free. The very design of the sensor/manually-controlled door, in this way, is displaced to the Post-it notes and the messages and drawings they carry. The Post-it notes, as such, come to work as markers of visibility (the door become visible), and as makers of an opening (push the button down there). In addition, the care workers come to partake in designing and re-configuring the house, while the Post-it notes come to partake in performing care work by way of sustaining a safe environment and independent living for the residents.

In a report by The Norwegian Directorate of Health we also find notions about independent living. It states that use of (health and care) welfare technologies within municipalities should regard the law of municipal health and care services as a baseline. This law, among other aims, seeks to: "[...] secure that the individual gets the possibility to live and reside independently and have an active and meaningful existence jointly with others" [30, p. 21. Translated from Norwegian].

(Example 2) Another example of in-and exclusion in design of technology concerns a light sensor in a flat. According to the resident, this sensor is too sensitive to movements and sounds, in that it automatically turns on the light in unwanted situations [31]. In order to avoid such experience of interference, the resident wraps silver foil around the sensor to block its workings "at inconvenient times." [31, p. 57]. See Fig. 3.

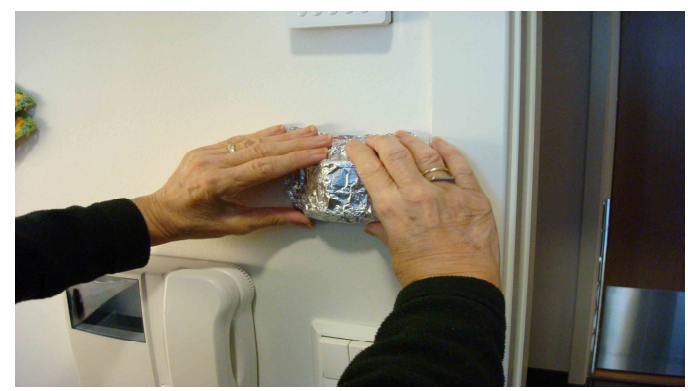

Fig. 3. A light sensor 'hacked' with foil. Photo: Finken

We read this situation as another example of how residents and employees of the house intervene in the design of technology to make it work. It matters what is inand excluded for independence to be in place. Within we could further add that a heterogeneity of independence and elderliness surfaces through our reading of this situation as intra-actions, that came about in a flat on a winter day in 2013 between a resident, care technology, mundane kitchen artifacts, and two field workers (the first author and a master student) who were asking questions, observing, and taking photos (field dairy, February 2013). 
(Example 3) Another example also illustrates how independence and elderliness are not fixed but rather vary according to the in- and exclusions in the design of the smart house with its digital care technologies, care workers, and residents. It was the spring of 2013 while introducing new master students to the house and its workings. Here we got to know that one of the residents spends most of the time in bed - only making a few visits to the bathroom and the kitchen (in the flat) - and cannot make the light turn on by moving the arms sufficiently enough to activate the sensor in the flat (field dairy, April 2013). Bringing in intra-action to analyze such situation also passes on understandings about independence and elderliness and how they come about in multiple relations between help from care workers, care technologies, and the residents him or her self. Thus, independency and elderliness are material-discursive phenomena enacted and acted on in different locations and times [5], [29].

With these examples from the smart house we want draw a parallel to design. Digital domestic care technologies feed on an idea of a homogenous group of citizens, through which the heterogeneity of older people also gets blurred. Callén et al. [32] make a similar point, stating that: "care technologies are generally used by people who have been considered to be vulnerable and in need of support." [p. 117]. Along these lines of thinking, there might as well be a blurring of the heterogeneity of users as described by Mort et al. [33] in their account of telecare. In the smart home, these users could be care personnel, residents, and relatives [12]. With respect to this we could say that the design of digital domestic care technologies, as many other technologies, builds on an ideal user, which, in practice, is a mere image [1]. A "user", or an old person or a care worker, in our case, is someone who becomes vis-à-vis technology - a someone who comes to perform as a specific "user" in order for the technology to do its caring job. With this we could say that independence is performed and intertwined with the discourses of society; thus, we find it fruitful to include performativity in design efforts, also when it concerns digital domestic care technologies.

Through the inclusion of normativity (e.g. what is expected of people of a certain age) and heterogeneity (e.g. various agencies) we learn that elderliness and independence is situated, coming into existence in various practices where discourses and materiality intra-act $[2,3]$. In the following we meet three senior citizens who imagine living with digital domestic care technologies.

\subsection{Imagining Digital Domestic Care Technologies}

The participatory design workshop was held in December 2011 with three seniors and two facilitators. At the workshop everyone introduced themselves to each other and the facilitators presented the aim of the workshop. The seniors were then asked to illustrate what a good day is like, what they are doing, and what kind of technologies they use. Following this activity, the next concerned sharing their illustrations. After the seniors had shared their stories about a good day, Maria, one of the facilitators, continued the workshop saying, "now, you have described your present day-to-day life, but can you imagine the future and how do you want life to be in the future and how do you expect things to work, then". 
Here we listen to Alma, August, and Beathe's imaginations of their futures. August starts the creation of future scenarios, he says with a laugh, "a walker that moves easily". Timers are also discussed. Beathe highlights the difficulties of installing a timer to a modern kitchen stove with knobs. To this, Alma points out: "no one has thought of that one wants a modern kitchen stove". They conclude that there is a gap between the development of domestic digital technologies and the timers at disposal.

All three explain their desire to stay in their homes, if possible, but they were also aware that they probably would be dependent on some kind of help in the future. August says: "at some point, the time appears when you become dependent on others but you do not want to think so far but you are aware it will appear."

Digital domestic care technologies such as alarms and sensors are designed and implemented in smart homes to facilitate seniors' daily life and independent living and autonomy. Alma, August and Beathe discuss also these kinds of technologies when Beathe insists that it is not only elderly people that are in need of reminders; younger people also use mobiles to remember activities. But they also touch upon more intimate aspects of their daily life, Beathe says:

do I manage to keep time, to ensure that, to cook food, what kind of help do I need to facilitate this, and ... last but not least do I manage to go to the bathroom, and take a shower, do we have toilets that work so I can ... the most embarrassing, I think, is being dependent on someone else to help me in the bathroom. It is absolutely the worst thing I know or are you forced to use diapers depending on that care workers cannot help you frequently enough - the most basic need, I think this is really important, one should start here [on basic needs] -other issues will also appear. Certainly one can focus on other issues but just to start, what do you need, you need food for the day and you need to go to the bathroom and you need ... here I think it is the absolute first and most important [demands], because many [services/technologies] do not exist and they [designers] don't care enough.

The lively conversation continues around issues that are important for making their desire to stay in their homes as long as possible - alarms and timers, but also more intimate issues were in focus.

Seniors' expertise of their day-to-day life with all that it entails was in focus both in the narratives and also in the scenario building [4]. However, they located themselves in relation to today's situation but were also able to imagine a higher degree of dependence on various kinds of digital domestic care technologies. Alarms, timers and sensors were technologies the seniors had relationships to although they were not dependent on them at the time when the workshop was held. In the imaginations, the participants situate themselves differently in relation to digital domestic care technologies. With a reading of their performances or intra-actions we identified both inand exclusion and how both independency and dependency unfolds [5]. Digital technologies' support and facilitation of remembering is not only a question of old or young. Both elderly and younger people are dependent on and use digital technologies. With the inclusion of mobiles and younger people remembering became not only a question for the workshop participants but also for other users. The participants the users -became subjects by identifying themselves with younger people [8]. The 
body's presence, its lesser degree of mobility, and an increased dependence were also brought up in the participants' imaginations of their futures. When mobility, dependence, and embarrassment were included in the performances the importance of intimacy appeared. The necessity to design digital domestic care technologies to assist older people (bodies that lack both motor and cognitive abilities) in the bathroom, was important to them. Being sensitive to the more intimate aspects of everyday life is a question of in- or exclusion or where the boundaries are drawn in design of digital domestic care technologies [5], [11]. An awareness of elderliness (as heterogeneous), of expertise (that of the old people with respect to their own life), and of normativity (which is inherent in design choices), will help designers to better appreciate that and how elderliness and independence are situated. This might help contest the image of an ideal user and to draw boundaries in design that include all aspects of old people's daily life.

\section{Discussion}

We have presented an alternative approach to understanding and examining interactions' between humans and technology [5]. We have been interested in understanding how 'elderliness' and 'independence' come about through intra-actions in which matter and discourse are accorded symmetrical analytical importance. In bringing [5] to serve as an analytical lens we have illustrated how the performance of independence is a process of becoming with digital care technology. Through such a reading there is no discrimination between subject/object. In other words, when performing elderliness in the smart home the person becomes an object to be sensed through its measureable presence or absence; independence becomes a specific, prescribed agency. Simultaneously, the technology becomes a subject with agency that acts (or not) on behalf of the object (the human). Subjects and objects, as such, are not prefixed from a standpoint of intra-action; rather, it is in their encounter with each other that they become and obtain their properties and boundaries [5]. The performativity of elderliness and independence is two-fold in the reading of the smart house and the workshop participants' imaginations, in that both subjects and objects are put to work in order for a more mutual relationship to unfold. The ideal user was also contested - elderliness is situated and unstable; it comes into existence in intra-actions dependent on what is included or excluded in design. For example, when mobile phones were included remembering emerged as a question of old and young. Dependency on other subjects and objects - humans or technologies - may also have implications for design, especially as a consequence of the human body's lack of abilities in particular contexts. Thus, it is a fruitful act to include more intimate aspects of day-to-day life when designing digital domestic care technologies. Older as well as younger people are subjects who become vis-à-vis digital technologies. Their being varies vary due to where they are located and what is included in the intraactions.

In closing, we find it fruitful to recap the ways in which the concept of intra-action can serve as an active ingredient within the design of digital technologies or digital 
domestic care technologies. First of all, in moving the view of use and design from 'interaction' to 'intra-action' the awareness is steered towards an understanding of being as contingent and constituted through ongoing practices and activities, rather than as a prevailing attribute that is stable and located within a specific entity. Thus, we ask for 'changing the gender of design' [34] in line with a Feminist Technoscience methodology that does not separate the discursive from the material, and, which accounts for a heterogeneity of agencies [5]. Within this we want to re-emphasize that there are no innocent positions. This also goes for care technologies; they are situated in use practices and are themselves practices of design. Thus questions about the in-and exclusions inherent in designs have a bearing on the potentials for that which can or might become.

Acknowledgements. Special thanks goes to care workers and participating senior citizens - this research would not have been possible without you letting us in to your world. Finken thanks The Norwegian Research Council for funding Autonomy and Automation in an IT society for All, grant \# 193172. Mörtberg thanks the Faculty of Technology, Linneaus University, for funding Sustainable Ways of Living with Technologies - designing with and for senior citizens and caregivers. Many thanks also to three anonymous HCC11 reviewers for constructive feedback and directions on how to sharpen our paper. We also owe thanks to Katie Vann for correcting our English. Preliminary results from the study in this paper have previously been presented orally at The First Nordic STS Conference, Norway, 2013; EASST, Denmark, 2012, and CHI 2012, USA.

\section{References}

1. Jansson, M., Mörtberg, C., Berg, E.: Old Dreams, New Means: an exploration of visionsand situated knowledge in information technology. Gender, Work and Organization 14, 371-387 (2007)

2. Genty, T.: Smart homes for people with neurological disability: State of the art. Neuro Rehabilitation 25, 209-217 (2009)

3. Remmers, H.: Environments for Ageing, Assistive Technology and Self-Determination: ethical perspectives. Informatics for Health \& Social Care 35(3-4), 200-210 (2010)

4. Brandt, E., Binder, T., Malmborg, L., Sokoler, T.: Communities of everyday practiceand situated elderliness as an approach to co-design for senior interaction. In: Proc. of CHI Special Interest Group of Australia on CHI, pp. 400-403. ACM, New York (2010)

5. Barad, K.: Meeting the universe halfway: quantum physics and the entanglement of matter and meaning. Duke University Press, Durham (2007)

6. Suchman, L.: Human-Machine Reconfigurations. Plans and Situated Actions, 2nd edn. Cambridge University Press, New York (2007)

7. Højgaard, L., Juelskjær, M., Søndergaard, D.M.: The 'WHAT OF' and the 'WHAT IF' of Agential Realism. - In Search of the Gendered Subject. Kvinder, Køn \& Forskning NR. 12, 67-78 (2012)

8. Hekman, S.: The Material of Knowledge. Feminist disclosures. Indiana University Press (2010) 
9. Bardzell, S., Bardzell, J.: Towards a Feminist HCI Methodology: Social Science, Feminism, and HCI. In: CHI 2011, pp. 675-684 (2011)

10. Markussen, R.: Politics of Intervention in Design: Feminist Reflections on the Scandinavian Tradition. AI \& Soc., 127-141 (1996)

11. Finken, S., Mörtberg, C.: The Thinking House: on configurings of an infrastructure of care. In: Proc. of the 3rd International Workshop on Infrastructures for Healthcare: Global Healthcare, June 23-24, pp. 44-47. The IT University of Copenhagen, Denmark (2011)

12. Finken, S.: HomeWork. Public care in private homes. In: Chandler, J., Barry, J., Berg, E. (eds.) Dilemmas for Human Services 2012, Papers from the 15th International Research Conference, London, September 1-2, pp. 32-39 (2011)

13. Thygesen, H.: Technology and good dementia care. A study of technology and ethics in everyday care practice. Ph.D. dissertation, Center for Technology, Innovation and Culture. Faculty of Social Sciences, University of Oslo, Norway (2009)

14. Roberts, C., Mort, M.: Reshaping what counts as care: Older people, work and newtechnologies. ALTER, European Journal of Disability Research 3, 138-158 (2009)

15. Aldrich, F.: Smart Homes: Past, Present and Future. In: Harper, R. (ed.) Inside the Smart Home, pp. 17-39. Springer (2003)

16. Bjørneby, S., Clatworthy, S., Thygesen, H.: Evaluering av BESTA-installasjon i Tønsberg. Report (1996)

17. Spingel, L.: Designing the Smart House: Posthuman Domesticity and Conspicuous Production. European Journal of Cultural Studies 8, 403-426 (2005)

18. Lopez, D., Callén, B., Tirado, F., Domènech, M.: How to become a guardian angel. Providing safety in a home telecare service. In: Mol, A., Moser, I., Pols, J. (eds.) Care in Practice. on Thinkering in Clinics, Homes and Farms. Transcript, pp. 73-91 (2010)

19. Fitzpatrick, G.: Keynote. In: 3rd International Workshop on Infrastructures for Healthcare: Global Healthcare, June 23-24. The IT University of Copenhagen, Denmark (2011)

20. Rapoport, M.: Being a body or having one: automated domestic technologies and corporeality. AI \&Soc. 28, 209-218 (2013)

21. Hollway, W.: Subjectivity and Method. In Psychology Gender, Meaning and Science. Sage Publications, London (1989)

22. Lather, P.: Postmodernism and the Human Science. In: Kavle, S. (ed.) Psychology and Postmodernism, pp. 88-109. Sage Publications, London (1992)

23. Mörtberg, C.: Heterogeneous images of (mobile) technologies and services: a feminist contribution. NORA - Nordic Journal of Feminist and Gender Research 11(3), 158-169 (2003)

24. Gunnarsson, E.: I think I have had a good life" - The everyday lives of older women and men in a life course perspective. Ageing \& Society 29, 33-48 (2009)

25. Elovaara, P., Mörtberg, C.: Cartographic Mappings: Participative Methods. In: Proc. of PDC, pp. 171-174. ACM (2010)

26. Elovaara, P., Igira, F.T., Mörtberg, C.: Whose Participation? Whose Knowledge? Exploring PD in Tanzania- Zanzibar and Sweden. In: Proc. of PDC, pp. 105-114. ACM (2006)

27. Field material collected from the local municipality concerning care plus

28. Finken, S.: Case Description - When Technologies Move to the Home. In: Bratteteig, T., Finken, S. (eds.) Book Based on the A3-Project "Autonomy and Automation in an ITSociety for All (to appear) (forthcoming)

29. Højgaard, L., Søndergaard, D.M.: Theorizing the complexities of discursive and material subjectivity: Agential realism and poststructural analyses. Theory \& Psychology 21, 338-354 (2011) 
30. Helsedirektoratet: Velferdsteknologi. Fagrapport om implementering av velferdsteknologi i de kommunale helse- ogomsorgstjenesterne 2012-2013 (2012),

http://helsedirektoratet.no/publikasjoner/velferdsteknologifagrapport-om-implementering-av-velferdsteknologi-i-dekommunale-helse-og-omsorgstjenestene-20132030 / Sider/default . aspx (retrieved online January 04, 2014)

31. Jørmeland, C.: Displacement in Care Technology Design. Master thesis. University of Oslo, Dept. of Informatics (August 2013)

32. Callén, B., Domènech, M., López, D., Tirado, F.: Telecare research (Cosmo)politizing methodology. ALTER, European Journal of Disability Research 3, 110-122 (2009)

33. Mort, M., Finch, T., May, C.: Making and Unmaking Telepatients: Identity and Governance in New Health. Science, Technology \& Human Values 34(9), 9-33 (2009)

34. Finken, S.: Changing the Gender of Design. In: Elovaara, P., Sefyrin, J., Öhman, M., Björkman, C. (eds.) Traveling Thoughtfulness - Feminist Technoscience Stories, pp. 85-93. Department of Informatics, Umeå University, Sweden (2010) 